\title{
The Professional Curriculum of Normal Class Educational Technology Based on Factor Analysis
}

\author{
Lv Saidong \\ Institute of Security \\ Yunnan Normal University \\ Kunming,Yunnan Province,China \\ lsdong_km@sina.com
}

\author{
Xia Yaowen and Xie Jili \\ Institute of Information \\ Yunnan Normal University \\ Kunming,Yunnan Province,China \\ xywen_km@sina.com
}

\begin{abstract}
Based on the factor analysis, this paper from the student's test scores perspective the normal education technology professional curriculum status firstly. Then it analyzes the existing of the advantages and disadvantages in the curriculum. Finally, it put forward the corresponding courses adjustment Suggestions so as to improve students' comprehensive ability and to satisfy the needs of the community.
\end{abstract}

Keywords-Factor Analysis, Education Technology,The Curriculum,Result, SPSS

\section{INTRODUCTION}

A large number of education information needed to use scientific statistical method to analyze along with the college expansion. Factor analysis as education information is a kind of multivariate statistical analysis, its basic idea is to use a few factor to describe the relationship between the multiple variables and it can make the multiple observation variable into a few not related comprehensive indicators, and the comprehensive index is often cannot be directly observed, but sometimes things are more can reflect the characteristics and nature. A professional course number is always very big, how will this great course boil down to a few ability target make the meaning clearer more representative? This is the very factor analysis can solve.

\section{THE METHOD OF FACTOR ANALYSIS}

Factor analysis is multivariate statistical analysis method of a kind of, in recent years, with the rapid development of the electronic computer, people will factor analysis method is successfully applied to various fields, making factor analysis theory and method more rich. Of course, the method of factor analysis in the education field of applied more and more.

\section{A. Factor analysis of the basic thought and basic principle}

The basic idea of factor analysis [1] is the cheek by jowl with the variable into the same category, and different types of the relationship between independent variables are lower. In the same category in the variable, can imagine is to be a common factor to influence each other high correlation, the common factor, also called the public factor, it is potential and cannot be observed. Factor analysis reflects a reducedorder thought, through the dimension reduction will be high correlation between the variables together, not only easy to extract the characteristics of easy to explain, and reduce the need analysis of variable number and the complexity of the problem analysis.

The basic principle of factor analysis [2] is based on correlation, from the covariance matrix or related matrix of most of the variation due to a few public factor for, and the remaining variation called special factors, so, each kind of variable actually represents a common factor, the basic features of factor analysis is used to find and determine the basic characteristics of the model.

\section{B. The basic model of factor analysis [3]}

Set for general $\bar{x}=\left(x_{1}, x_{2}, \ldots \ldots, x_{p}\right)^{\prime}$, the mean vector $E(\bar{x})=\bar{\mu}$ And covariance matrix $V=\left(\sigma_{i j}\right)_{p \times p}$ both exist. Factor model of the general form for record: $\left\{\begin{array}{l}x_{1}=a_{11} F_{1}+a_{12} F_{2}+\ldots \ldots+a_{1 m} F_{m}+\varepsilon_{1} \\ x_{2}=a_{21} F_{1}+a_{22} F_{2} \ldots \ldots+a_{2 m} F_{m}+\varepsilon_{2} \\ \ldots \ldots \ldots \ldots \\ x_{p}=a_{p 1} F_{1}+a_{p 2} F_{2}+\ldots \ldots+a_{p m} F m+\varepsilon_{p}\end{array}\right.$

Each symbol is the following meaning:

- $\mathrm{F}_{1}, \mathrm{~F}_{2}, \ldots . ., \mathrm{F}_{\mathrm{m}}$ : Standardization of the observable evaluation index decomposition out independent public factor, they are not observed, its meaning according to the specific circumstances to explain.

- $\varepsilon_{1}, \varepsilon_{2}, \ldots \ldots \varepsilon_{p}$ : Is the corresponding index $X_{i}$ Unique factor, called special factors, It says $X_{i}$ in public factor can be part of the explanation, $a_{i j}$ is the first $\mathrm{i}$ a indicators in the first $\mathrm{j}$ a common factor of coefficient, known as the factor loading.

(1) type can be used formula for said: $X=L F+\varepsilon$. Each symbol is the following meaning:

$$
\begin{aligned}
& X=\left(x_{1}, x_{2}, \ldots \ldots, x_{p}\right)^{\prime} ; \mathrm{F}=\left(\mathrm{F}_{1}, \mathrm{~F}_{2}, \ldots . ., \mathrm{F}_{\mathrm{m}}\right)^{\prime} \\
& \mathcal{E}=\left(\varepsilon_{1}, \varepsilon_{2}, \ldots . \varepsilon_{p}\right)^{\prime}
\end{aligned}
$$


$L=\left[\begin{array}{cccc}a_{11} & a_{12} & \ldots & a_{1 m} \\ a_{21} & a_{22} & \ldots & a_{2 m} \\ \ldots & \ldots & \ldots & \ldots \\ a_{p 1} & a_{p 2} & \ldots & a_{p m}\end{array}\right]$

The statistical significance of factor loading matrix [1]:

- $a_{i j}$ : Is the first $\mathrm{i}$ an index and $\mathrm{j}$ a common factor $F_{j}$ of the correlation coefficient, It says the linear between $x_{i}$ and $F_{j}$ correlation degree. The first matrix I did the first element that I A index $X_{i}$ depends on the degree of public factor, and A first $\mathrm{j}$ $F_{j}$ column element said Ming first $j$ a public factor and each index contact degree, usually according to $a_{i j}$ size to explain the meaning of public factor.

- A first I do elements of the sum of squares called index $X_{i}$ common degrees [4], namely $h_{i}^{2}=\sum_{j=1}^{m} a_{i j}^{2}$

,By orthogonal factor model, there is $\operatorname{var}\left(x_{i}\right)=\sum_{j=1}^{m} a_{i j}{ }^{2} \operatorname{var}\left(F_{j}\right)+\operatorname{var}\left(\varepsilon_{i}\right)$ namely, $1=h_{i}{ }^{2}+\operatorname{var}\left(\varepsilon_{i}\right)$. Thus communalities $h_{i}{ }^{2}$ said all m a public factors on index $x_{i}$ of the total variance contribution $h_{i}^{2}, x_{i}$ said the original information is $\mathrm{m}$ a common factor that up to the higher level.

- A first $\mathrm{j}$ column element sum of squares said the first j A public factors $F_{i}$ on original index provides total variance contribution, namely, $g_{j}=\sum_{i=1}^{p} a_{i j}{ }^{2} \quad F_{j}$ the original index variance contribution for

$$
a_{j}=\frac{g_{j}}{\sum_{i=1}^{p} \operatorname{var}\left(x_{j}\right)}=\frac{g_{j}}{p}=\frac{1}{p} \sum_{i=1}^{p} a_{i j}{ }^{2}
$$

;The factor

$$
F_{j} \text { first } \mathrm{j} \text { a common factor that the more important. }
$$

\section{THE METHOD OF FACTOR APPLICATION}

Taking my school level 2011 education technology professional (normal class) fifty students 32 compulsory course in the first three years of the test scores as the basic material, from students the performance analysis of education technology professional curriculum situation.

The original data from college students' archives management. Scores for points, and the minimum score unit 1 , the corresponding due to lack of discipline, such as test cause course no results, recorded as zero; For make-up, remember the last time the make-up examination results, data format as is shown in table 1.

\begin{tabular}{|c|c|c|c|c|c|c|c|}
\hline 课程 & $\begin{array}{l}\text { 大 } \\
\text { 学 } \\
\text { 语 } \\
\text { 文 }\end{array}$ & $\begin{array}{l}\text { 大 } \\
\text { 学 } \\
\text { 体 } \\
\text { 育 }\end{array}$ & $\begin{array}{l}\text { 数 } \\
\text { 据 } \\
\text { 结 } \\
\text { 构 }\end{array}$ & $\begin{array}{l}\text { 艺 } \\
\text { 术 } \\
\text { 基 } \\
\text { 础 }\end{array}$ & $\begin{array}{l}\text { 教 } \\
\text { 育 } \\
\text { 传 } \\
\text { 播 } \\
\text { 学 }\end{array}$ & $\begin{array}{l}\text { 数 } \\
\text { 字 } \\
\text { 逻 } \\
\text { 辑 } \\
\text { 系 } \\
\text { 统 }\end{array}$ & $\begin{array}{l}\text { 数 } \\
\text { 据 } \\
\text { 库 } \\
\text { 应 } \\
\text { 用 }\end{array}$ \\
\hline 044100201 & 93 & 82 & 79 & 79 & 90 & 71 & 78 \\
\hline 044100202 & 90 & 85 & 83 & 84 & 88 & 63 & 70 \\
\hline 044100203 & 77 & 62 & 89 & 90 & 76 & 73 & 67 \\
\hline ....... & ....... & ....... & $\cdots \cdots$ & $\cdots \cdots$ & $\cdots \cdots$ & $\cdots \cdots$ & $\cdots \cdots$ \\
\hline
\end{tabular}

TABLE I. ORIGINAL DATA SHEET

The brief overview statistical information as shown in figure 1 shows, the processed data are 47 cases is effective.

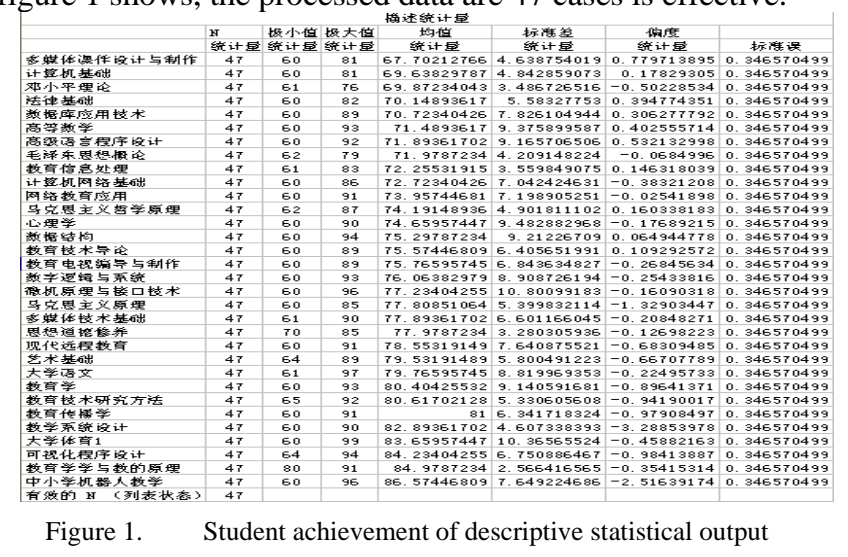

IV. SPSS FACTOR ANALYSIS MODELING AND ANALYSIS

\section{A. SPSS parameter Settings}

In turn, click on the menu - Analyze Data Reduction Factor..... Executive factor analysis process, in the Variable list will be in addition to student id outside of all Variable elected to the Variable (s) list as analysis Variable. Which factor extraction method choice principal component method, factor rotation methods select variance maximum rotation method.

\section{B. Output results}

Initial variable correlation test. As shown in figure 2 shows, multiple variables between the correlation coefficient is bigger, these variables that between the more significant correlation, and also shows that a necessary factor analysis is carried out. 


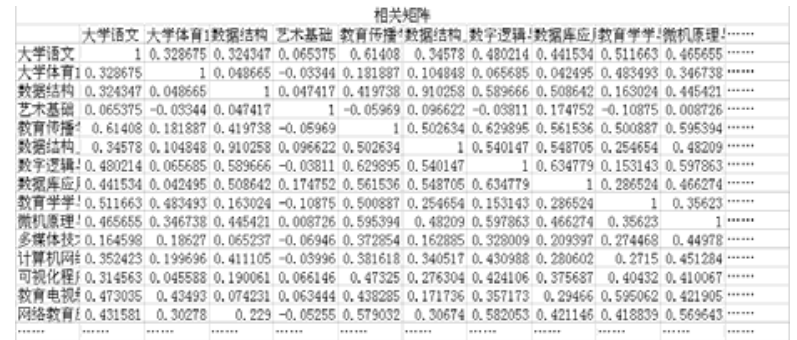

Figure 2. Correlation matrix overview

KMO inspection and Bartlett spherical inspection. As shown in figure 3 shows, KMO test [6] research between variables of partial correlation, partial correlation calculation when controlling for other factors, so than simple correlation coefficient is small, general KMO statistic is greater than 0.9 effect best, more than 0.7 can accept, 0.5 the following is unfavorable for factor analysis, and in this case KMO value close to $0.9,0.897$ for further proved the feasibility of the factor analysis. Bartlett spherical inspection (7) statistic Sig value is less than 0.01 , the negative correlation matrix for unit array of the null hypothesis that the variable is a significant correlation between the correlation matrix, from the conclusion of the agreement.

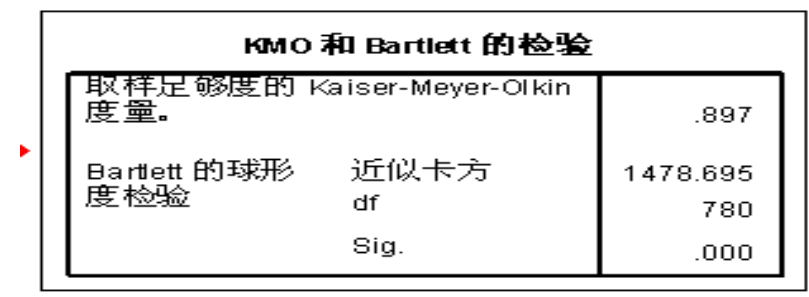

Figure 3. KMO inspection and Bartlett ball check output

Variance explained table. As shown in figure 4 shows, "the total variance" [8] form gives each common factor had explained variance and its accumulated and. Observation "initial characteristic value" column of "cumulative \%" column, the top 12 common factor to explain the accumulative total variance is $78.611 \%$, that is to say the 12 common factor can explain the original variable contains $78.611 \%$ of the information. "Extraction sum of squares load" column said without rotation, from the 12 common factor their variance contribution rate information, they and the "initial characteristic value" column of the first 12 column value, for the 12 common factor can explain $78.611 \%$ of the total variance.

说明的总方差

\begin{tabular}{|c|c|c|c|c|c|c|}
\hline \multirow[b]{2}{*}{ 成分 } & \multirow{2}{*}{\multicolumn{3}{|c|}{ 初始特征值 }} & \multirow{2}{*}{\multicolumn{3}{|c|}{ 提取平方和载入 }} \\
\hline & & & & 合计 & & 累积\% \\
\hline 1 & 13.182 & 32.956 & 32.956 & 13.182 & 32.956 & 32.956 \\
\hline 2 & 2.806 & 7.016 & 39.972 & 2.806 & 7.016 & 39.972 \\
\hline 3 & 2.293 & 5.734 & 45.706 & 2.293 & 5.734 & 45.706 \\
\hline 4 & 1.996 & 4.990 & 50.696 & 1.996 & 4.990 & 50.696 \\
\hline 5 & 1.880 & 4.699 & 55.395 & 1.880 & 4.699 & 55.395 \\
\hline 6 & 1.654 & 4.135 & 59.530 & 1.654 & 4.135 & 59.530 \\
\hline 7 & 1.512 & 3.780 & 63.311 & 1.512 & 3.780 & 63.311 \\
\hline 8 & 1.416 & 3.540 & 66.850 & 1.416 & 3.540 & 66.850 \\
\hline 9 & 1.356 & 3.389 & 70.240 & 1.356 & 3.389 & 70.240 \\
\hline 10 & 1.204 & 3.009 & 73.249 & 1.204 & 3.009 & 73.249 \\
\hline 11 & 1.106 & 2.766 & 76.015 & 1.106 & 2.766 & 76.015 \\
\hline 12 & 1.039 & 2.596 & 78.611 & 1.039 & 2.596 & 78.611 \\
\hline
\end{tabular}

Figure 4. Variance explain output table
Load matrix. As shown in figure 5 shows, through the observation can be found in this case extraction twelve common factor, the first factor of load look, education information processing, education system design, microcomputer principle and interface technology, digital logic and system, network education application, education and communication six courses have great positive load, these courses are education technology the basis of professional course, therefore the first factor can be defined as the basic theory and computer application factor, and its variance accounted for $32.956 \%$, occupy the first position, in that each common factor, the first factor of the component heaviest, also the most in need; From the second common factor of load look, education television director and production, teaching measurement and evaluation, education study and teaching principle, visual programming four course have larger is load, and data structure, introduction to MAO zedong thought, higher mathematics, ideological and moral cultivation four course in the second common factor have more negative load, especially education television playwright-director is in the second common factor to 0.507 is load, the data structure of 0.414 points the negative load, so the two course open to education technology professional it is very necessary. Can take the second common factor defined as education ability basis and computer programming factor; In the third common factor, the information technology teaching method, teaching measurement and evaluation, modern distance education, teaching system design, information technology and curriculum integration five courses have larger is load and negative load, can the third common factor defined as information literacy ability factor, i.e., access to information, information analysis, information processing and information utilization ability, today is a information society, information literacy for everyone is very important, for education technology professional students is particularly important, so it is necessary to open these courses; In the fourth common factor, psychology have higher negative load, psychology as a teacher must have a course in the teaching process, students' psychological speculation is very important, so let the future teachers to learn this course is very necessary, can be defined fourth common factor for speculation ability factor; Education technology introduction and primary and secondary school robot teaching two courses in the fifth factor of large load, education technology education technology introduction is a compulsory course, it is also education technology professional of introductory courses. Undergraduate course education technology students the jobs of the future in primary and secondary schools to most, along with the development of society, the robot teaching in primary and secondary schools, so learning robot teaching this course is very necessary, it could be defined as education technology of basic factor; In the sixth common factor, education technology research methods, network education application, education to learn and teach of principle and so on to have large negative load, the teacher in the daily teaching is not only to teach and teach, in has a strong teaching ability at the same time should also have a certain scientific research ability, therefore, open education 
technology research method is particularly important, can the sixth common factor defined as scientific research ability factor; In the seventh common factor, computer maintenance and maintenance of large load, the teacher should not only make full use of computer serves for the teaching, but also should have some basic knowledge of computer maintenance, or a little bit of problems are likely to make the teaching work hard to smoothly, the seventh common factor defined as computer management factor; Education measurement and evaluation in the first ten common factor in have greater negative load, how to judge the stand or fall of quality education needs scientific education measurement and evaluation of the knowledge as the guidance, only the scientific education measurement and evaluation, to improve teaching and teaching management work, so which can be defined as the teaching quality discriminate factor.

Marxism political economics and Marxism philosophy in the first common factor, the second common factor and the eighth common factor has larger load that set up the two courses is very necessary. College Chinese language and literature, legal basis, den Xiaoping theory, MAO Zedong thought and introduction to a few course, in all the common factor of the load is less, this a few course is a basic literacy, but the basic literacy formation is a long, slow process, rely on the university learning is not enough, and students usually don't study and to test a back to back through, no to enhance the purpose of quality, so the necessity to open such little. Campus network construction and management, digital video system two subjects in each common factor of load is small, the two course features is a professional is too strong, also need strong basic computer you can learn it well, so education technology students in learning the two course time there may be a lot of difficulty, so will the open for elective course is more reasonable.

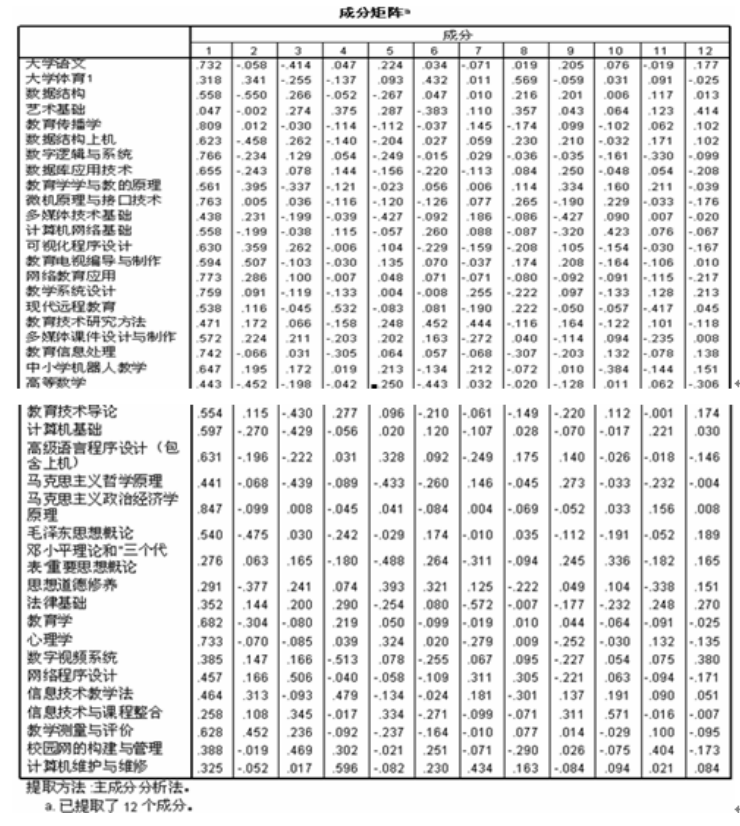

Figure 5. Factor loading matrix

\section{CONCLUSIONS}

According to above using factor analysis method from the perspective of students' test scores to education technology professional curriculum analysis, we can see that normal colleges education technology professional curriculum should pay attention to teaching ability, information literacy, computer application and maintenance, teaching design ability, research ability and practice ability training. Through the factor analysis from the Angle of quantitative curriculum situation analysis, to overcome the traditional single to qualitative analysis of the shortcomings, so as to optimize the normal colleges and universities education technology professional curriculum. Factor analysis in agriculture, medicine, aviation, etc has been quite widely used, but in the education field of application but is not enough mature, are not perfect, has yet to be made after thorough research.

\section{ACKNOWLEDGMENT}

This work is supported by the National NSF of China (No.60903131), the key project of the Education Bureau Youth Fund of Yunnan Province (No.07Z1066).

\section{REFERENCES}

[1] Mi Hong, Zhang Wenzhang. Practical, modern statistical analysis method and SPSS application. Contemporary China publishing house. 2000 (10).

[2] Wang Hong. Principal component analysis in the application of teaching evaluation. Journal of shanxi normal university (natural science edition), 2006 (6) : 2-14.

[3] Wang fang. Principal component analysis and factor analysis of the similarities and differences compare and application [J] statistical education. 2003 (5) : 14 - 17.

[4] Chen Xuedong. Education practice assessment of multivariate statistical solutions [J].journal of mathematical statistics and management. 2003.22 (6) : 1-4.

[5] Yang Xiaoming editor. The application of SPSS in education statistics [M]. Beijing: higher education press. 2004.278-286.

[6] Du Jiang. SPSS statistical analysis savvy [M]. People's posts and telecommunications publishing house. 2009.03.

[7] Pan Xianyun. Teaching in the study of multivariate analysis trial [J]. Journal of guangzhou university (comprehensive edition). 2000.14 (3) : 86-88.

[8] Mao Yue. Student appraisal of teaching, the result of statistical analysis [D]. 2007.01 